\title{
Comparison of the Uptake of Cadmium Ion on Chitosan and Chitosan/2,7 - Naphthalenediol Nanocomposite
}

\author{
Solomon Sunday Durodola ${ }^{1,}$, , Sheriff Adewuyi ${ }^{2}$, Odunayo Timothy Ore ${ }^{1}$ \\ ${ }^{1}$ Department of Chemistry, Obafemi Awolowo University, Ile-Ife, Nigeria \\ ${ }^{2}$ Department of Chemistry, Federal University of Agriculture, Abeokuta, Nigeria
}

Email address:

solomonsun77@gmail.com (S. S. Durodola)

${ }^{*}$ Corresponding author

\section{To cite this article:}

Solomon Sunday Durodola, Sheriff Adewuyi, Odunayo Timothy Ore. Comparison of the Uptake of Cadmium Ion on Chitosan and Chitosan/2,7 - Naphthalenediol Nanocomposite. International Journal of Photochemistry and Photobiology. Vol. 4, No. 1, 2020, pp. 17-20. doi: $10.11648 /$ j.ijpp.20200401.13

Received: December 5, 2019; Accepted: January 2, 2020; Published: January 10, 2020

\begin{abstract}
Risk to human health arising from intake of heavy metals in foods and water is of great concern, one of the major application of chitosan and its derivative is its ability to chelate strongly metal ions. This adsorption capacity could be increased by crosslinking or forming its nanocomposite. In this research study, chitosan/2,7 - naphthalenediol nanocomposite was formed, the nanocomposite was characterized using FTIR spectrophotometer and UV/Visible spectrophotometer. The adsorption of cadmium ion by the nanocomposite and chitosan alone was studied for comparison using $\mathrm{CdCl}_{2}$ solution containing Cd (II) ions. Amount of cadmium ion adsorb by each of them was studied at different time interval and evaluated using atomic absorption spectrophotometer (AAS). Results showed that chitosan/2,7 - naphthalenediol nanocomposite would adsorb maximum $\mathrm{Cd}^{2+}$ concentration of $0.017 \mathrm{mg} / \mathrm{g}$ at 20 minutes stirring time, while chitosan alone would adsorb maximum $\mathrm{Cd}^{2+}$ concentration of $0.016 \mathrm{mg} / \mathrm{g}$ at 10 minutes stirring time. It is therefore concluded from this study that both the chitosan and the nanocomposite have demonstrated almost the same degree of efficiency towards the removal of $\mathrm{Cd}^{2+}$ ion from aqueous medium and therefore both can be used in the treatment or removal of heavy metal ions from industrial effluents and other waste water.
\end{abstract}

Keywords: Chitosan/2,7-Naphthalenediol, Nanocomposite, Adsorbed, Cadmium Ion

\section{Introduction}

Determination of trace metals is of interest because while some are essential nutrients some are toxic. Metals like zinc, manganese, copper, chromium, iron and cobalt are essential trace elements for humans, animals and plants [1]. On the other hand, lead, cadmium, nickel, arsenic and mercury etc are toxic even at low levels. The need to estimate the levels of these metals in materials or samples have increased tremendously after reports on different roles they play in human health and disease [1].

A good number of industries are responsible for the release of heavy metals into the environment through their wastewater [2]. Some of these heavy metals are extremely toxic elements and can seriously affect many living species especially human. Duffus reported that heavy metals are metals that have shown to be harmful and toxic to the human body [3, 4] and constitute a major public health concern $[5,6]$. These metals could cause acute and chronic toxicity by various modes of action in both children and adults $[7,8]$. Lead in the body affects the nervous system, kidneys and blood [9]. Removal of these metals from wastewater is important, among the many other low cost absorbents identified; Chitosan has the highest sorption capacity for several metal ions because they possess a number of different functional groups such as hydroxyls and amines to which metal ions can bind either by chemical or by physical adsorption [10-12]. Its adsorption performance can be further improved by cross linking with reagents which can stabilize it in acid solution and increase its mechanical properties. [13].

Chitosan is a transformed polysaccharide obtained by deacetylation of natural chitin, which is the structural 
element in exoskeleton of crustaceans (Crabs, Shrimps, etc) and cell walls of fungi [14]. It is hydrophilic, nontoxic, biodegradable and biocompatible material with the ability to form complexes with metals, due to the presence of amino groups on the polymer matrix, which can interact with metal ions of the solution by ion exchange or other complexation reactions (mainly chelation). The insolubility of chitosan in aqueous and organic solvents is a result of its crystalline structure, which is attributed to extensive intramolecular and intermolecular hydrogen bonding between the chains and sheets, respectively. Cadmium has been reported to be toxic at certain threshold levels, the need therefore arises to investigate the use of synthetic adsorbents in the removal of cadmium ion from aqueous system.

\section{Material and Methods}

\subsection{Synthesis of Chitosan/2,7 - Naphthalenediol Nanocomposite}

$1.2 \mathrm{~g}$ of 2,7 - naphthalenediol was dissolved in $20 \mathrm{ml}$ of distilled water and stirred, using magnetic stirrer for 1 hour. $0.8 \mathrm{~g}$ of chitosan was dissolved separately in $40 \mathrm{ml}$ of 0.10 molar $\mathrm{HCl}$. The dissolved 2,7 - naphthalenediol was added to the chitosan in the presence of CDI (carbodiimide) as a catalyst and stirred for $10 \mathrm{mins}$. The $\mathrm{PH}$ of the reaction mixture was adjusted to 6.5 with 0.10 $\mathrm{M} \mathrm{NaOH}$ solution and stirred at room temperature for 24 hour. It was then filtered, the residue was air dried and stored in desiccator. It was then characterized using Nicholet 1S5 FTIR.

\subsection{Comparison Between Adsorption of Cadmium Ions on Chitosan and the Nanocomposite}

$20 \mathrm{mg} / \mathrm{L}$ cadmium solution was prepared using analytical grade $\mathrm{CdCl}_{2}$ powder. $20 \mathrm{ml}$ of the $\mathrm{CdCl}_{2}$ solution was taken and $20 \mathrm{mg}$ of chitosan was added. Then the mixture was continuously stirred using magnetic stirrer for 10 minutes. The same procedure was repeated and stirred for 20 minutes and 40 minutes respectively. Each of the solution was filtered and the filtrates were analyzed using atomic adsorption spectroscopy to determine amount of cadmium absorbed by chitosan.

The same steps were repeated using Chitosan/2,7 naphthalenediol nanocomposite, to determine amount of cadmium absorbed by the nanocomposite respectively.

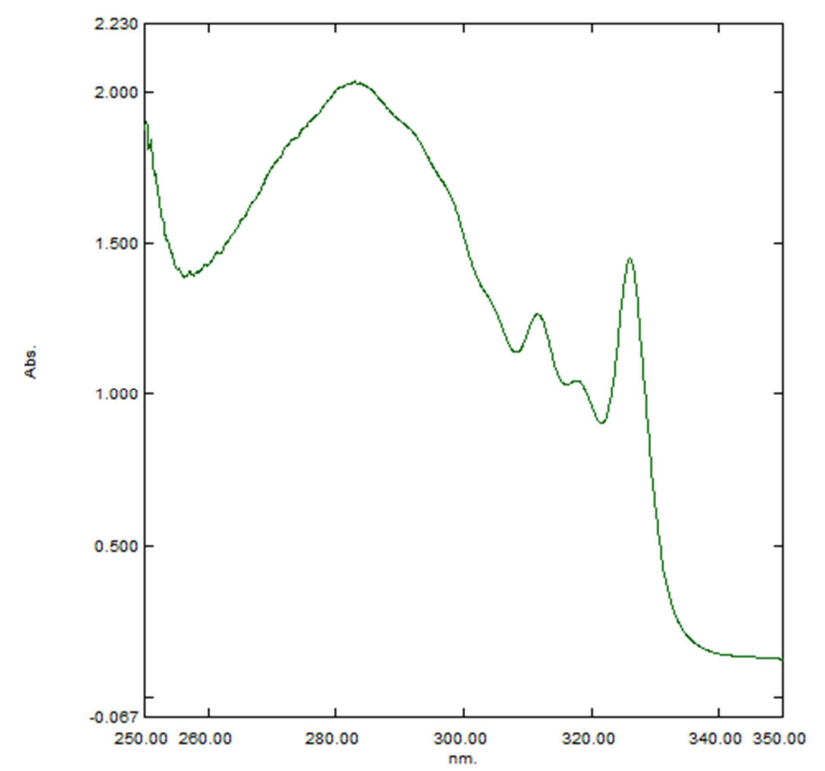

Figure 1. UV -Visible spectrum of Chitosan/2,7 - Naphthalenediol Nanocomposite.

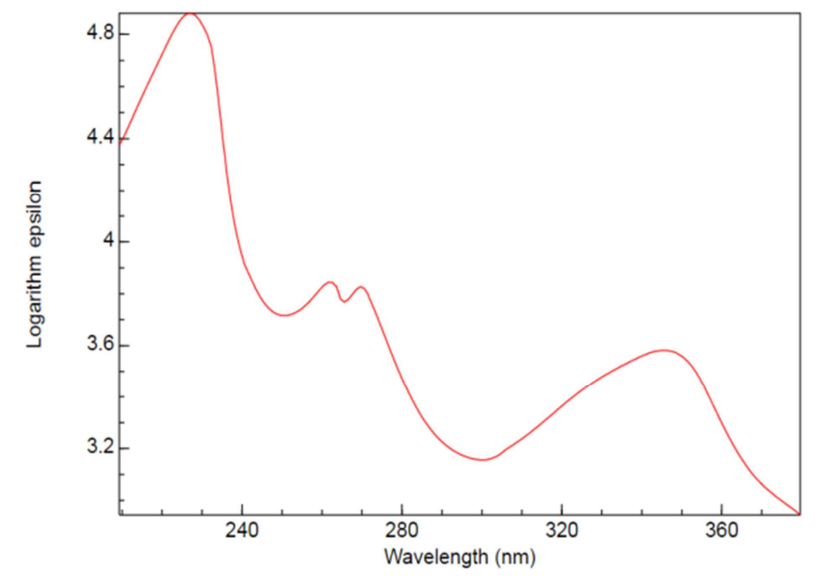

Figure 2. UV/Visible spectra of 2,7 - naphthalenediol (http://webbook.nist.gov/chemistry).

\section{Results and Discussion}

\subsection{Concentration of Cadmium Ion Adsorbed}

The Table below show the concentration of cadmium ion adsorbed by chitosan and the nanocomposite respectively after addition of $20 \mathrm{mg}$ of each adsorbent to $20 \mathrm{~mL}$ of the solution containing $20 \mathrm{mg} \mathrm{CdCl}_{2}$ and stirred for $10 \mathrm{mins}$, 20 mins and 40 mins.

Table 1. Concentration of Cadmium ion Adsorbed.

\begin{tabular}{lll}
\hline $\begin{array}{l}\text { Concentration of } \mathbf{C d}^{2+} \text { adsorbed by chitosan } \\
(\mathbf{m g} / \mathbf{g})\end{array}$ & $\begin{array}{l}\text { Concentration of } \mathbf{C d}^{2+} \text { adsorbed chitosan/2,7 - naphthalenediol } \\
\text { nanocomposite }(\mathbf{m g} / \mathbf{g})\end{array}$ & $\begin{array}{l}\text { Time of stirring } \\
(\mathbf{m i n u t e s})\end{array}$ \\
\hline 0.016 & 0.001 & 10 \\
0.009 & 0.017 & 20 \\
0.006 & 0.005 & 40 \\
\hline
\end{tabular}

\subsection{Efficiency of the two Adsorbent.}

It was observed that both chitosan and the nanocomposite adsorb heavy metals, in this case, cadmium ions. The nanocomposite adsorbed cadmium ions within concentration range of 0.001 to $0.017 \mathrm{mg} / \mathrm{g}$. A maximum $\mathrm{Cd}^{2+}$ 
concentration of $0.017 \mathrm{mg} / \mathrm{g}$ was adsorbed at 20 minutes and this value represent the utmost concentration the adsorbent can attain before saturation set in. The adsorbing behaviour of the chitosan/2,7 - naphthalenediol nanocomposite decreases for 40 mins stirring time. Similar result was obtained using pure chitosan as an adsorbent. In this case, a maximum $\mathrm{Cd}^{2+}$ concentration of $0.016 \mathrm{mg} / \mathrm{g}$ was adsorbed at 10 minutes stirring time after which saturation occur and the removal efficiency of the adsorbent decreases for 20 minutes, and further decrease was observed for 40 minutes stirring time. However it is important to emphasise from this study that there is practically no difference in the maximum amount of cadmium ion that can be removed from aqueous solution using the two adsorbent (chitosan $(0.016 \mathrm{mg} / \mathrm{g})$ and chitosan/2,7 - naphthalenediol nanocomposite $(0.017 \mathrm{mg} / \mathrm{g})$. Cadmium has been found to be associated with skeletal damage [15]. It is also discovered that it is detrimental to reproductive system and embryonic development [16], while prolonged exposure to cadmium could cause nausea, vomiting, and abdominal pain among others [17].

It is therefore more economical and involves minimum procedures if chitosan alone is used for $\mathrm{Cd}^{2+}$ ion clean up from aqueous medium including industrial effluents since its adsorbing efficiency compare favourably with what was obtained using chitosan/2,7 - naphthalenediol nanocomposite. The ability of chitosan to adsorb metal ions is due to the presence of free amino group. In addition, the high chelating ability of chitosan also comes from its hydroxyl and ether groups [18].

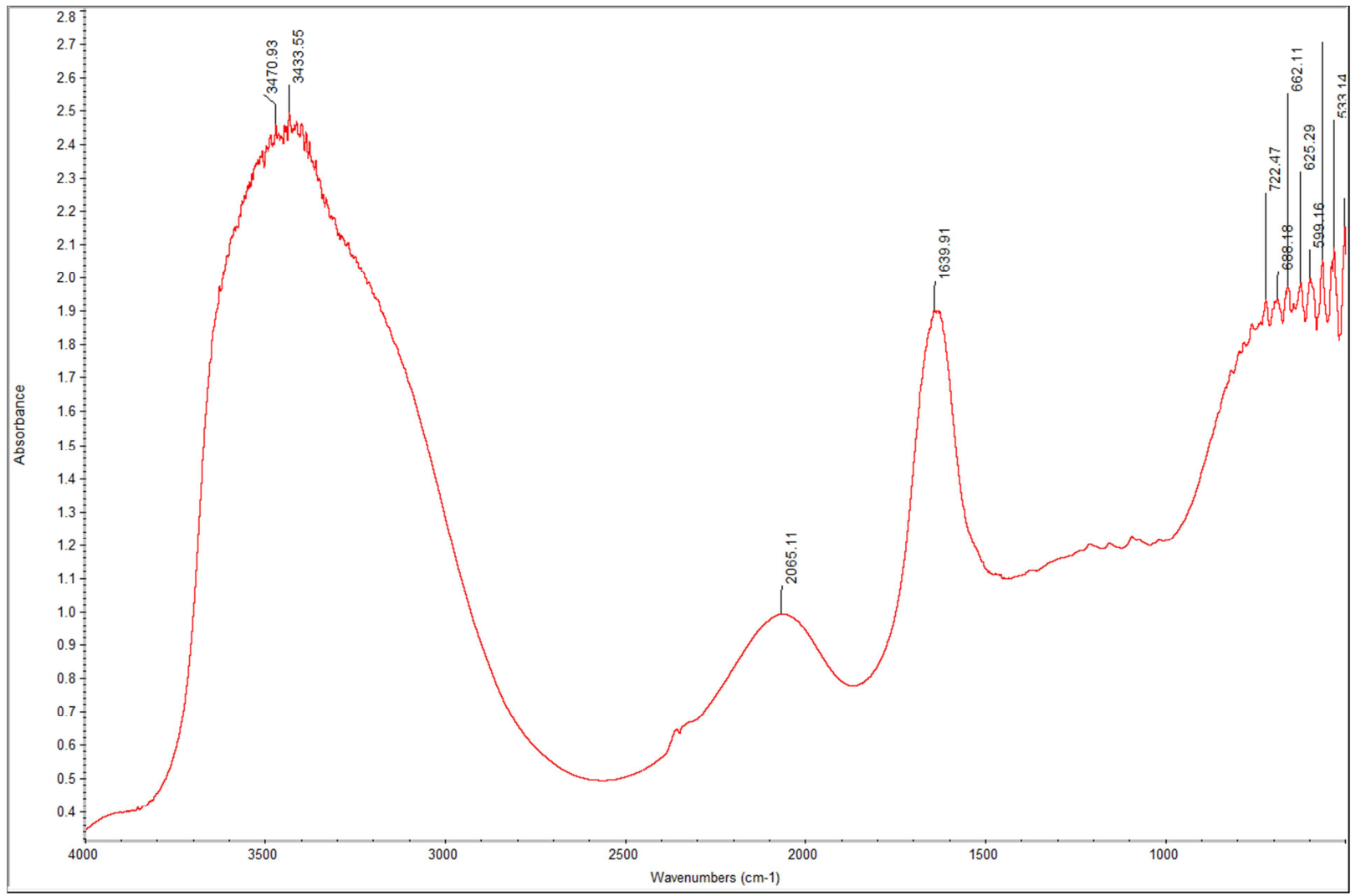

Figure 3. IR spectra of the Chitosan/2,7 - naphthalenediol nanocomposite.

\section{Conclusion}

Since the efficiency of both the chitosan and the nanocomposite is nearly the same towards the removal of $\mathrm{Cd}^{2+}$ ion, therefore both of them could be used for the treatment or removal of cadmium ion and other heavy metal ions from industrial effluents and other waste water.

\section{References}

[1] Okoye. C. O. B, Chukwuneke. A. M, Ekere. N. R. and Ihedioha. J. N. 2013. Simultaneous ultraviolet-visible (UVVIS) spectrophotometric quantitative determination of $\mathrm{Pb}, \mathrm{Hg}$, $\mathrm{Cd}$, As and $\mathrm{Ni}$ ions in aqueous solutions using cyanidin as a chromogenic reagent.
[2] Quek S. Y, Wased A. J and Forster C. F, 1998. The use of sago waste for the sorption of lead and copper. Water SA 24 (3) $251-256$.

[3] Life Extention. Heavy Metal Toxicity, http://www.lef.org/ (updated 06.12.03).

[4] J. H. Duffus 2002. Heavy metal, a meaningless term Pure Appl. Chem. 74 793-807.

[5] Bingol M., Yentur G., Buket E. R., Oktem A. B. 2010. Determination of someheavy metal levels in soft drinks from Turkey using ICP-OES method, Czech J. Food Sci. 28 213216.

[6] Cabrera C., Lorenzo M. L., Lopaz M. C. 1995. Lead and cadmium contamination in dairy product and its repercussion on total dietary intake, J. Agric. Food Chem. 43 1605-1609. 
[7] Ibrahim D., Froberg B., Wolf A., Rusyniak D. E. 2006. Heavy metal poisoning: clinical presentations and pathophysiology, Clin. Lab. Med. 26 67-97.

[8] Berry W. L., Wallace A., Toxicity 1981. The Concept and Relationship to the Dose-Response Curve.

[9] Assi, M. A., Mohd, N. M., Mohd, N., Abd, W. H., Mohd, Y., Mohd, A. R., 2016. The detrimental effects of lead on human and animal health. Vet. World 9, 660.

[10] Deans J. R and Dixon. B. G 1992. Uptake of $\mathrm{Pb}^{2+}$ and $\mathrm{Cu}^{2+}$ by novel biopolymers. Water Res. 26 (4) 469-472.

[11] Findon A, Mckay G, and Blair H S 1993. Transport studies for the sorption of copper ions by chitosan. J. of Environ. Sci. and Health A28 (1) 173-185.

[12] Bailey S. E, Olin T. J, Bricka R. M, and Adrian D. D. 1999. Water Research, 33 (11), 2469-2479.

[13] George Z. K and Eleni A. D. 2013. Mercury (II) Removal with Modified Magnetic Chitosan Adsorbents. Molecules ISSN. page 6194 .

[14] Madhavan P. and K. G. R. Nair (1974). Utilization of prawn waste: Isolation of Chitin and its conversionto chitosan. Fish. Technol., 11-50.

[15] Jãrup, L., 2003. Hazards of heavy metal contamination. Br. Med. Bull. 68, 1167-1182.

[16] Thompson, J., Bannigan, J., 2008. Cadmium: toxic effects on the reproductive system and the embryo. Reprod. Toxicol. 25 (3), 304-315.

[17] Hodgson, E., 2010. A Textbook of Modern Toxicology, Fourth Edition. Wiley, USA, p. 648.

[18] Shenhsiung Lin, Chia-Chen Chang and Chii-Wann Lin (2012). A reversible optical sensor based on chitosan film for the selective detection of copper ions. Biomedical Engineering, applications, basis and communications, Vol. 24. 